STRUCTURED ABSTRACT

IGIP

IGIP/ICL CONFERENCE

\title{
Modbus Protocol as Gateway between different Fieldbus devices - a Didactic Approach
}

\author{
Armando Cordeiro, Paulo Costa, V. Fernão Pires \\ ADEEEA - Área Departamental de Engenharia Eletrotécnica, Energia e Automação \\ ISEL - Instituto Superior de Engenharia de Lisboa, Rua Conselheiro Emídio Navarro 1, \\ 1959-007 Lisboa, PT \\ acordeiro@deea.isel.pt; pauloarcosta81@gmail.com \\ DEE - Departamento de Engenharia Eletrotécnica \\ ESTSetúbal-Instituto Politécnico Setúbal Campus do IPS, Estefanilha, 2914-761 Setúbal, PT \\ vitor.pires@estsetubal.ips.pt;
}

\begin{abstract}
This paper is dedicated to improve the skills of Electric Engineering students about Industrial Automation. This is done creating a set of practical exercises in the laboratory that allow students to interact with didactic and industrial equipment understanding the compatibility problems and give students the tools, the knowledge and even some creative freedom to solve problems that happens in real situations. In this case, it was focuses in the interconnection of equipment from different manufacturers using the Modbus protocol. To allow to the students this practical study, it was developed a solution with a Modbus RTU protocol directly implemented in program memory of both S7-200 (using the Freeport configuration mode) and S7300 PLCs. The solution allows a gateway between Modbus-TCP (over a Master TSX PLC from Schneider-Electric) and Profibus-DP (over a Master S7-300 PLC from Siemens).
\end{abstract}

\section{KEYWORDS}

Fieldbus devices; Modbus RTU, Modbus TCP 


\section{CONTEXT}

This paper is dedicated to improve the skills of Electric Engineering students about Industrial Automation. This is done creating a set of practical exercises in the laboratory that allow students to interact with didactic and industrial equipment understanding the compatibility problems and give students the tools, the knowledge and even some creative freedom to solve problems that happens in real situations.

\section{GOAL}

This paper presents a solution to interconnecting equipment from different manufacturers using the Modbus protocol implemented in software. The main objective of the present work was not to create a better solution than those ones proposed by manufacturers, but to provide advanced training for Industrial Automation students to master aspects related to interrupts, timeouts, data synchronization, watchdogs, subroutines, direct and indirect addressing, buffering, among other aspects of fieldbus communications.

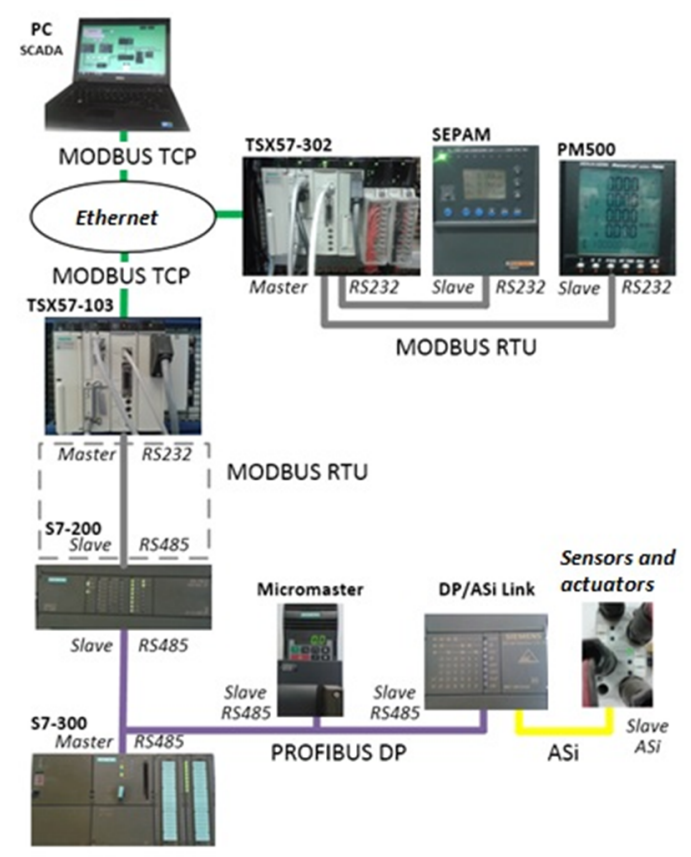

Fig. 1. Proposed solution to integrate fieldbus devices from different manufactures.

\section{APPROACH}

In terms of education about theory of fieldbus systems students are encouraged to learn different aspects, namely: 
- Principles of communication theory (communication techniques, codification, modulations, topologies, data rates, media access methods, etc.);

- Fieldbuses for Industrial Automation;

- Commonly used Fieldbus standards (physical layer standard, media supported, maximum nodes, deterministic, intrinsically safe, maximum segment length, etc.);

- Describe the network processes that use protocols and how they utilize them;

- Identify the functions of protocols and protocol stacks;

- Map specific protocols to the appropriate OSI layer.

In order to consolidate theoretical knowledge about fieldbus systems several practical experiments are normally proposed. Some experiments are dedicated to simple RS-232 communications through half-duplex transmissions using Modbus RTU. Others are dedicated to more complex configuration of fieldbus communication devices such as Profibus-DP using RS-485 or WorldFip using IEC61158 as physical layer standard. Usually, the students who attend the Master degree in Electrical Engineering and want a specific expertise at Industrial Automation it is normally proposed a more advanced practical experiment such as described in this paper.

\section{ACTUAL OR ANTICIPATED OUTCOMES}

The use of laboratories is essential to consolidate theoretical knowledge in engineering. With this type of experiments students are better prepared to deal with practical problems that happens in real situations and in their professional life, increasing their self-esteem and selfconfidence. Employee feedback shows that this should be a way forward in training good engineering professionals.

\section{CONCLUSIONS}

The objective of the present study was to create a solution to integrate several devices from different manufactures without purchase specific hardware interfaces, providing training to future Electric Engineers to solve problems of this nature. To achieve this objective it was necessary to study and understand the devices and the protocols and create a specific solution 
to deal with the compatibility problems. As expected, the most complex problem to solve was the communication between the MODBUS RTU protocol used by the TSX57103 controller and the PROFIBUS-DP network used by the S7 controllers. It was necessary to program the S7-200 PLC to behave as a gateway between this two networks. This was very difficult because the S7 200 is a slave device in both networks. To solve this problem were used memory buffers in S7 PLCs combined with indirect readings cycles to detect the presence of new messages. Also the generic control programs of the S7 PLCs (with main concern in the S7 200) must be optimized to avoid messages timeout. For very long and not optimized generic control program is not always possible to succeed in communications. This is the one of the main disadvantage of the proposed solution. Students who participate in this kind of experience are better prepared for their professional life with regard to industrial automation.

\section{REFERENCES}

[1] V. Vyatkin, "Software Engineering in Industrial Automation: State-of-the-Art Review," IEEE Trans. Ind. Informatics, Vol. 9, no. 3, Aug. 2013, pp. 1234-1249.

[2] F. Benzi, G. Buja, M. Felser, "Communication Architectures for Electrical Drives," IEEE Trans. Ind. Informatics, Vol. 1, no. 1, Feb. 2005, pp. 47-53.

[3] M. Felser and T. Sauter, "The fieldbus war: history or short break between battles?," in Proc. IEEE Int. Workshop Factory Commun. Syst., 2002, pp. 73-80.

[4] J. Weigmann, G. Kilian, Decentralization with profibus-DP: Architecture and fundamentals, configuration and use with SIMATIC S7, Verlag: Publicis MCD, 2000, ISBN: 3-89578-144-4.

[5] R. Al-Dalky, O. Abduljaleel, K. Salah, H. Otrok, M. Al-Qutayri, "A Modbus traffic generator for evaluating the security of SCADA systems," in Proc. 9th IEEE International Symposium on Communication Systems, Networks \& Digital Signal Processing (CSNDSP), 23 Jul - 25 Jul 2014, Manchester, UK.

[6] A.C.D. Bonganay, J.C. Magno, A.G. Marcellana, J.M.E. Morante, N.G. Perez, "Automated electric meter reading and monitoring system using ZigBee-integrated raspberry Pi single board computer via Modbus," in Proc. IEEE Students' Conference on Electrical, Electronics and Computer Science (SCEECS), 1-2 March 2014, Bhopal, India. 
[7] S. Tamboli, M. Rawale, R. Thoraiet, S. Agashe, "Implementation of Modbus RTU and Modbus TCP communication using Siemens S7-1200 PLC for batch process," in Proc. IEEE International Conference on Smart Technologies and Management for Computing, Communication, Controls, Energy and Materials (ICSTM), 6-8 May 2015, Chennai, India.

[8] "Introduction to Modbus Serial and Modbus TCP", Vol. 9, Issue 5 Sept-Oct.2008, the Extention, a technical supplement to control network, 2008 Contemporary Control Systems, Inc.

[9] A. Daneels; W. Salter, "What is SCADA?," in Proc. International Conference on Accelerator and Large Experimental Physics Control Systems, 1999, Trieste, Italy.

[10] G. Clarke, D. Reynders, E. Wright, Practical Modern SCADA Protocols: DNP3, IEC60870.5 and Related Systems, Elsevier, $1^{\text {st }}$ ed. 2004. 